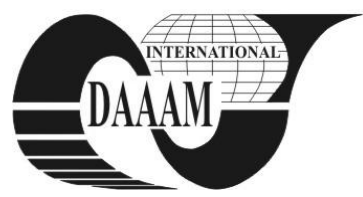

Annals of DAAAM for 2011 \& Proceedings of the 22nd International DAAAM Symposium, Volume 22, No. 1, ISSN 1726-9679 ISBN 978-3-901509-83-4, Editor B. Katalinic, Published by DAAAM International, Vienna, Austria, EU, 2011 Make Harmony between Technology and Nature, and Your Mind will Fly Free as a Bird Annals \& Proceedings of DAAAM International 2011

\title{
ROUGHNESS BASED STUDY OF MILLED COMPOSITE SURFACES
}

\author{
MARCOS, M[ariano]; GOMEZ - LOPEZ, A[ntonio] J[ose]; BATISTA PONCE, M[oises]; SALGUERO, J[orge] \\ \& GAMEZ, A[ntonio] J[uan]
}

\begin{abstract}
This work reports on the results of a study of the surface roughness of Carbon Fiber based composite sheets after a milling process carried out with WC circular inserts partially covered by PCD (Polycrystalline Diamond). An analysis based on the influence of the cutting parameters has been achieved. Results obtained from this analysis have shown that surface roughness of the machined samples have high dependence on cutting depth. A parametric model has been proposed for establishing a relationship between average roughness, $R a$, and cutting depth, $d$.
\end{abstract}

Key words: milling, roughness, composites, carbon fiber, cutting depth

\section{INTRODUCTION}

Currently, Non Metal Matrix Composites (NMMC) are widely applied in different industrial sector because of their excellent relationship mechanical properties/weight. In particular, this relationship has been taken advantage by the aerospace industry [1]. So, nowadays, a high percentage of the structural elements of the airships are constructed using this kind of materials, mainly in Carbon Fiber/Epoxy Resin composites.

Commonly, in a high number of aerospace production processes, the NMMC based elements have to be subjected to different machining processes, mainly drilling and milling $[1,2]$.

Dry drilling of a high variety of aeronautical NMMC's based workpieces have been widely studied by a considerable number of researchers, not only by conventional drilling [1-5] but also by non-traditional drilling processes such as abrasive waterjet machining (AWJM) and laser drilling [6,7].

Contour milling is other of the processes commonly applied in the production of NMMC based aerospace structural elements. Again, different research studies can be found on these processes applying either conventional milling, or High Speed Milling (HSM), or laser milling, or AWJM [1,3,6,7].

However, there is a lack of studies on the horizontal-plane milling of those materials.

The most of aerospace pieces are pre-manufactured with dimensions close to definitive ones. In spite of this, frequently it is necessary to make a final adjustment to tolerances requirements. This adjustment is commonly made by horizontal-plane milling (frontal). In this case, some of the main surface damages are related with the relative orientation cutting direction/fiber placement. Fig. 1 shows a scheme of the $\mathrm{CF}$ cutting for different relative positions cutting-fiber directions.

In the present work, a study of the surface roughness of Carbon Fiber based composite sheets after a horizontal-plane milling process has been performed. An analysis based on the influence of the cutting parameters (cutting speed, feed, and depth of cut) has been carried out.

\section{EXPERIMENTAL PROCEDURE}

Polymeric Resin/Carbon Fiber based NMMC plates $(1000 \times 300 \times 11 \mathrm{~mm})$ have been used as workpieces in the experimental stage of this study. This material has a plain interlaced thread to thread weave, Fig. 2, with content in resin of 42 per cent.
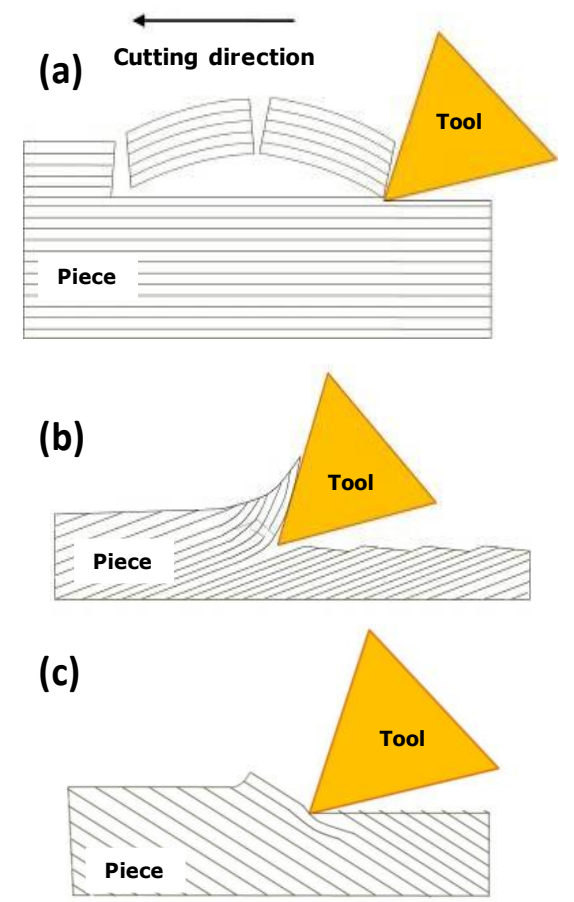

Fig. 1. Orthogonal cutting of NMMC with (a) fiber parallel to cutting direction; (b) fiber placement in cutting opposition; (c) fiber placement in fiber concordance

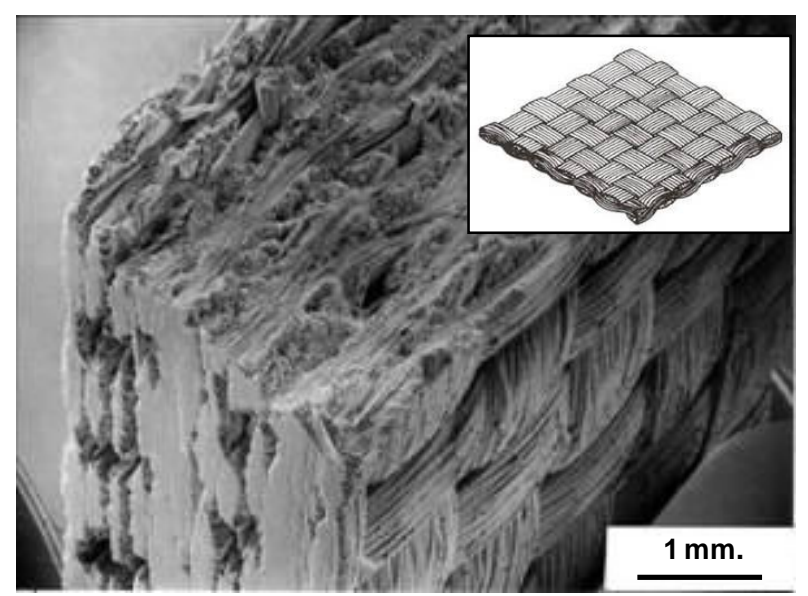

Fig. 2. NMMC sample used in the millling tests 
A six edges-six insert mill of $50 \mathrm{~mm}$ diameter was used as cutting tool, Fig 3(a). Inserts were selected as $10 \mathrm{~mm}$ diameter cylindrical WC-Co inserts partially covered (30\%) by a Polycrystalline Diamond (PCD) coating, Fig 3(b).

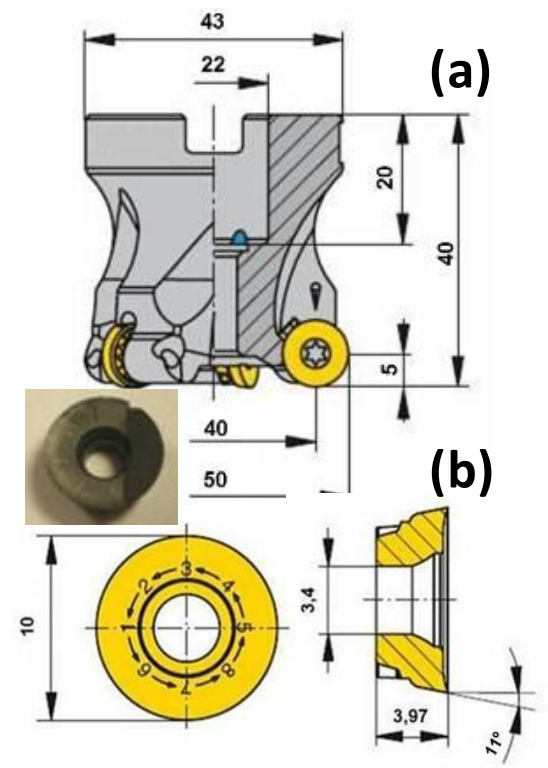

Fig. 3. Cutting tools using in the milling tests

Horizontal-plane (frontal) milling tests were carried out in a SNK Horizontal Machining Center, model HPS.120 B. Different cutting speed $\left(\mathrm{V}_{\mathrm{c}}\right)$ from 900 to $1300 \mathrm{~m} / \mathrm{min}$ and feedrate $\left(\mathrm{V}_{\mathrm{f}}\right)$ from $2400-19100 \mathrm{~mm} / \mathrm{min}$ were selected and combined for cutting depths between 1 and $4 \mathrm{~mm}$. Roughness measurements $(\mathrm{Ra})$ were carried out using a Mahr Perthometer M2 Profilometer.

\section{RESULTS AND DISCUSSION}

Fig. 4 includes an image of a sample after being dry frontal milled at $900 \mathrm{~m} / \mathrm{min}$. As it can be observed, surface defects can be related to some discontinuities in the interlaced threads disposition. These defects can be provoked by a lack of resin pre-impregnation in the sheets.

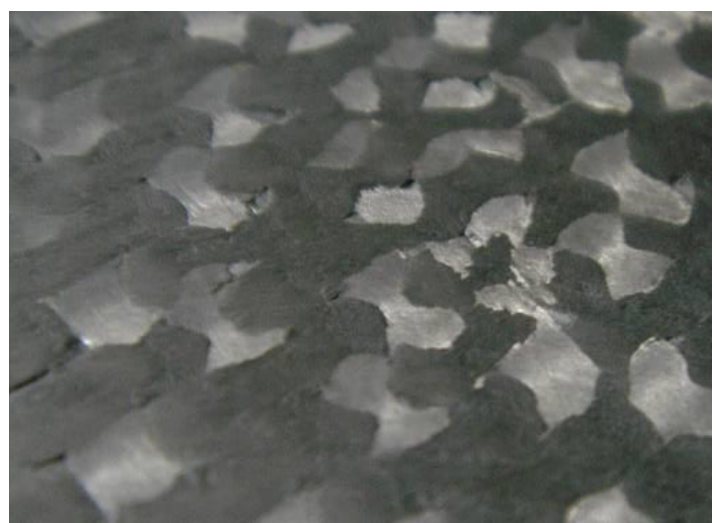

Fig. 4. Characteristic aspect of a frontal milled sample surface

Notwithstanding, this defect is reduced with the depth of cut. In effect, Fig. 5 plots the evolution of the average roughness, $\mathrm{Ra}$. As it can be appreciated in this figure, the value of the average roughness diminishes as depth of cutting increases. Looking at the same figure, it can be observed that the influence of the cutting speed on $\mathrm{Ra}$ is much smoother, although it is appreciable a light decreasing of $\mathrm{Ra}$ when $\mathrm{V}_{\mathrm{c}}$ increases.On the other hand, as it can be expected, in the most of cases feedrate influences negatively on $\mathrm{Ra}$, except when lowest values of feedrate $\mathrm{V}_{\mathrm{f}}$, and cutting speed, $\mathrm{V}_{c}$, are combined. In the Literature is very difficult to find works where $\mathrm{Ra}$ and depth are related, especially in the analysis of the machining of NMMC's.

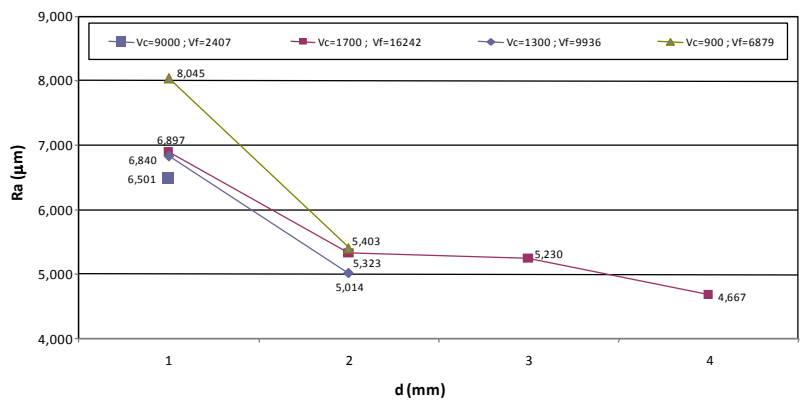

Fig. 5. Evolution of Ra as a function of depth of cut

From these results, it is possible to propose a potential parametric model in the same way that others previously developed for $\mathrm{V}_{\mathrm{c}}$ and $\mathrm{V}_{\mathrm{f}}$ in the study of other materials.

$$
\mathrm{Ra}=6.76 \cdot \mathrm{d}^{-0.27}
$$

This equation reveals the tendency of Ra to decrease as d increases.

\section{CONCLUSIONS}

A study of the influence of the depth of cut on the workpieces surface quality in the frontal milling of Carbon Fiber/Resin (40-60) composites has been carried out in this work. The loss of quality has been associated with emerging defect in the interlaced fibers caused by the manufacturing process and by the milling process. This loss of surface quality -measured through Ra- is higher when small depths of cut are applied. A potential parametric model has been proposed. On the other hand $V_{c}$ and $V_{f}$ affect smoothly to changes in Ra.

\section{ACKNOWLEDGEMENTS}

This work has received financial support from the Spanish Government project DPI2008-06771-C04-01 and from the Andalusian Government. Author thank to Airbus Military the support in the experimental stage of this work

\section{REFERENCES}

M. Álvarez, M. Batista, J. Salguero, M. Sánchez Carrilero, M. Marcos (2010) Low Environmental Impact Machining Processes of Composite Materials Applied to the Aerospace Sector, Advanced Materials Research (107) 15-19

A.M. Abrão, P.E. Faria, J.C. Campos Rubio, P. Reis, J. Paulo Davim (2007) Drilling of fiber reinforced plastic, Journal of Materials Processing Technologies (186) 1-7

S. Abrate, D.A. Walton (1992) Machining of Composite Materials. Part I: Traditional Methods. Composites Manufacturing (3) 75-83

C.C. Tsao (2009) Experimental Study of Drilling Composites with Step-Core Drill, Materials \& Design (3) 1740-1744

Sanjay Rawat, Helmi Attia (2009) Wear Mechanisms and Tool Life Management of WC-Co Drills during Dry High Speed Drilling of Woven Carbon Fiber Composites, Wear (267) 1022-1030

S. Abrate, D.A. Walton (1992) Machining of Composite Materials. Part II: Non-Traditional Methods. Composites Manufacturing (3) 85-94

J. Folkes (2009) Waterjet-An Innovative Tool for Manufacturing. Journal of Materials Processing Technologies (20) 6181-6189 